\title{
Compressive strenght of hybrid composites and nanofilled composites after post curing using light box
}

\author{
Tirza Rizany*, Mohammad Richata Fadil*, Endang Sukartini* \\ *Department of Conservative Dentistry Faculty of Dentistry Universitas Padjadjaran
}

\section{ABSTRACT}

Introduction: Nanofilled composite resins and resin hybrid composites are often used for the manufacture of composite indirect restorations because it has the addition of filler to add strength materials. This study aimed to compare the compressive strength of composites and composite hybrid nanofilled after post curing using light box. Methods: The research conducted was experimental research, with samples divided into two groups of each 10 specimens of hybrid composite resin and nanofilled. Composite cylindrical diameter of $3 \mathrm{~mm}$ and $6 \mathrm{~mm}$ high in post-curing for 180 seconds using a light box compressive strength test was then performed using a Lloyd Instruments LRX Plus, $1 \mathrm{~mm} / \mathrm{mnt}$ speed. Results: The results were the average compressive strength of post-curing hybrid composites 234.61 $\mathrm{MPa}$ higher than the average post-curing composite nanofilled that was $196.60 \mathrm{MPa}$. Conclusion: the compressive strength of hybrid composite after post curing with light box is greater than the nanofilled composite.

Keywords: Composite nanofilled, hybrid composite, compressive strength

\section{INTRODUCTION}

Composite resin fillings are frequently used in dentistry because it has a good aesthetic value, low price and adheres well to the tooth structure when compared with ceramic material. Composite resin material has several advantages over other materials because of the workable time, so the operator can control and apply the patch material. ${ }^{8}$ Hybrid composite material is a material that has a viscosity like amalgam filling material. The hybrid composite has an inorganic filler of 75-85\% which makes the composite restoration stronger and resistant to wear. Nowadays The development of composite materials is very fast both physically, mechanically and esthetically. The nanofilled composite is one of the results. The nanofilled composite material has resistance to chewing force and excellent esthetics because it has more staining to match the original teeth and the ability to absorb. The nanofilled material has advantages in compressive strength, tank strength and fracture resistance when compared to hybrid composite materials, microhybrid and microfill. ${ }^{14}$

Indoor composite restoration is polymerized using light-curing unit. Polymerization still persists even after the irradiation has been completed. The polymerization will be complemented by the use of heating techniques. The heating technique will enhance the resin matrix of the filler and increase the conversion of the monomer so that the composite is stronger and produce a more stable color due to its better homogeneity. ${ }^{1,2}$ Increased adhesion of resin matrices will strengthen the 
composite mechanical properties including tensile strength and compressive pressures in indirect composite restorations. ${ }^{9-10}$ Lombardo et al (2007) argue that the strength of indirect polymerization composite restorations using light-curing units and combined with heating techniques will improve the mechanical properties of composite materials. Completion of the indirect composite restoration polymerization is enhanced with the help of lightbox tools. Lightbox is a cube-shaped tool measuring $4 \mathrm{~cm}$ made of mirrors. This device works to produce energy to make the composite resin matrix polymerization perfect after polymerization using light curing unit.

Based on the above matters the authors are interested in researhing the compressive strength difference between hybrid composite resins with nanofilled resin composites polymerized using light box for indirect composite restoration. This study aimed to compare the compressive strength of composites and composite hybrid nanofilled after post curing using light box.

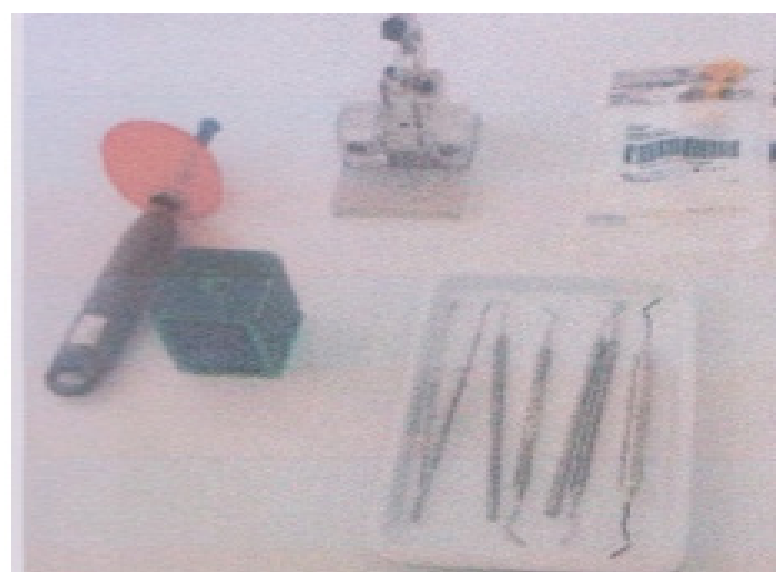

Figure 2 . Materials and research tools

\section{METHODS}

The type of this research was experimental research. The materials used are Nanofilled composite resins (Z350.3MEE) and Hybrid composite resins (P60, 3MEpe). The tool used was a $3 \mathrm{~mm}$ diameter and $6 \mathrm{~mm}$ diameter composite mold, composite instrument, LED light-curing unit, lightbox, LRX Plus Llyod Instrument. The population of this study was resin composite restorative material with criteria having hybrid and nanofilled fillers, while the samples in this study were 10 hybrid composite resin specimens and 10 specimens of nanofilled composite resins. As many as 20 specimens of $3 \mathrm{~mm}$ in diameter and $6 \mathrm{~mm}$ in height, randomly selected into two groups. Group I with Hybrid Composite while Group II with Nanofilled composite. Each specimen after obtaining treatment was given activation by using LED Light curing unit for 20 seconds. After that for each specimen post curing using a light box for 180 seconds as post-curing. Each specimen corresponding to its group was measured by its compressive strength.

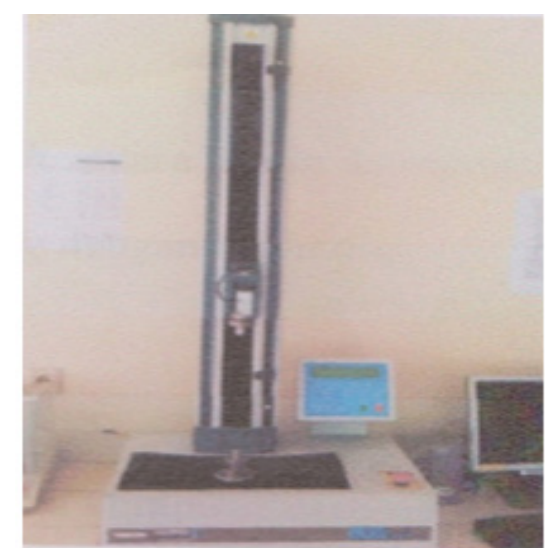

Figure 3 Pressure strength tester machine (Irx plus lloyod instrument)

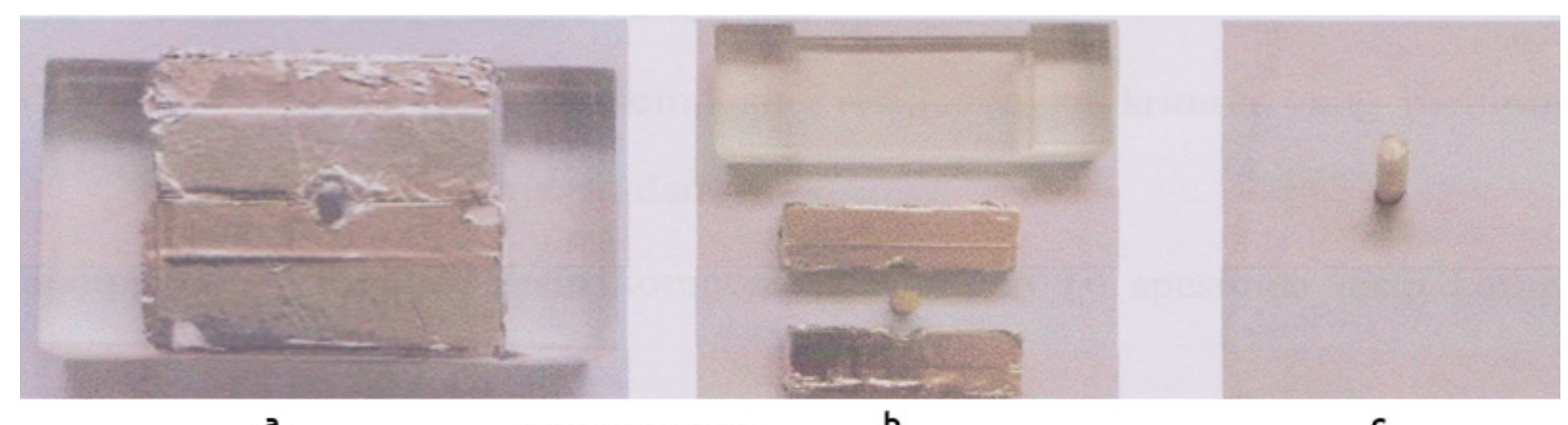

a.

b.

c.

Figure 1.A The sample mold is made of fibers coated with aluminum foil paper with a cylindrical centered hole in the center of the sample, B: the sample is removed from the mold and C: the composite sample drawing 


\section{RESULTS}

The control group used 1 hybrid composite specimen and 1 nanofilled composite specimen in post curing using dry heating with temperature $f$ $110^{\circ} \mathrm{C}-140^{\circ} \mathrm{C}$ for 7 minutes. Each specimen is measured in compressive strength, the result shown in table 1.

Table 2 above showed $t$ arithmetic amounted to 2,82 with p-value $<0.01$. This implies that the test results are significant or both values of different compressive strengths. Of the 10 samples in the

Table 1. Test Results Compressive strength of Hybrid Composite Group and Nanofilled Composites

\begin{tabular}{ccc}
\hline $\begin{array}{c}\text { No } \\
\text { Sample }\end{array}$ & $\begin{array}{c}\text { Composite Hybrid } \\
\text { Compressive Strength } \\
(\mathrm{MPa})\end{array}$ & $\begin{array}{c}\text { Nanofilled Composites } \\
\text { Compressive Strength (MPa) }\end{array}$ \\
\hline 1 & 203.07 & 227.15 \\
2 & 199.59 & 151.93 \\
3 & 272.31 & 193.43 \\
4 & 200.27 & 165.62 \\
5 & 267.67 & 244.44 \\
6 & 262.31 & 209.95 \\
7 & 207.13 & 202.32 \\
8 & 276.07 & 190.76 \\
9 & 215.26 & 201.67 \\
10 & 242.38 & 178.76 \\
\hline
\end{tabular}

Table 2. Statistical analysis Two equality test equations between Hybrid composite compressive strength and nanofilled composites

\begin{tabular}{llll}
\hline Statistic & $\mathrm{n}$ & mean & STDEV \\
\hline Nanofilled composite & 10 & 196,60 & 27,44 \\
Hybrid composite & 10 & 234,61 & 32,64 \\
\hline 18 & Df & \\
38,003 & difference (Hybrid-nanofilled) & \\
909.280 & pooled variance \\
13.485 & standard error of difference \\
0.000 & Hypothesized difference \\
2.10 & t tabel ( 95\%) 2.82 t hitung \\
0057 & p-value (one-tailed) & \\
0114 & p-value (two-tailed)
\end{tabular}

Table 3. Compressive tests of hybrid composites and nanofilled compositeswith post curing using dry strelisators

\begin{tabular}{lll}
\hline Sample & $\begin{array}{l}\text { Compressive } \\
\text { strength of hybrid } \\
\text { composites (Mpa) }\end{array}$ & $\begin{array}{l}\text { Compressive strength of } \\
\text { nanofilled composites } \\
\text { (Mpa) }\end{array}$ \\
\hline 1 & 243.45 & 279.02 \\
\hline
\end{tabular}

two test groups, the average composite strength of the hybrid composite was $234,61 \mathrm{MPa}$ and the composite strength of nanofilled composite. These results show that there is an average difference composite compressive strength. The compressive strength of the hybrid composite group is greater than that of the composite strength of the nano filled composite group

From table 3 as control, it showed that nanofilled composites was better than hybrid composites at compressive tests with post curing using dry strelisators.

\section{DISCUSSION}

The results showed that there was a composite compressive strength difference between hybrid and nanofilled, this was demonstrated with significant results in both groups of composite resins (table 1 ). The average composite strength of hybrid composite type is higher than that of nanofilled resin composite because the hybrid composite resin has a larger filler size that is the combination of physical and mechanical properties of two particles to be better that is macrofilled and microfilled 12.2.5.5.

Filler material is a glass of brosilicate glass, lithium or barium aluminum silicate, and strontium or zinc glass) of $0.6-1 \mu \mathrm{m}$ and 0.04 $\mu \mathrm{m}$ silica colloidal filler serves to provide filler strength, resulting in the spread of rays and small amounts of rays that increase the translusions resembles an email with particle size. The number of fillers $75-80 \%$ of the total composite volume so that the compressive strength of hybrid composite is higher and composite polishing is better. ${ }^{2.5}$

Whereas in nanofilled composite resins the particle size is smaller ie, nanomeric particles and nanocluster. Nanomeric is a very small nano particles of silica with a size of 2570 nanometers shrouded in a silane compound so that it is perfectly bonded with a resin matrix. The nanocluster particle is a $\mathrm{Zr}$ or $\mathrm{Si}$ particle measuring 0.4-1 micrometres incorporated $\mathrm{SiO}_{2}$ and $\mathrm{ZrO} 2$ bonded together. The incorporation of two particles to reduce the space between particles makes polishing easier, better and finer surfaces. 1.2.4.5.6 The result of Kllymus et al (2007) study using cylindrical specimen diameter $3 \mathrm{~mm}$ and height $6 \mathrm{~mm}$ with post curing for 180 seconds 
using light curing unit showed that compression strength test using Artglass composite (herauz kulzer) with $68 \%$ filler material, BelleGlass Composite (Kerr) with an $87 \%$ filler and a solidex (shofit) composite with a filler of $53 \%$. The results show composite Art glass $224.00 \mathrm{MPa}$, composite Solidex 206.70 MPA and BelleGlass 163.02 MPa Composite this describes the form of larger filler will be better compression strength in compare the form of smaller filler.

The average result of hybrid composite compressive strength test $234.61 \mathrm{MPa}$ (table 2 ), was inn accordance with the mechanical properties of dental materials ie on the 250-290 MPa hybrid composite. This result is almost close to the mechanical properties of amalgam material that is $300-500 \mathrm{MPa}^{7}{ }^{7}$ The result of composite control group conducted post curing using dry heating (table 3 ) indicates that composite strength of nanofilled composite is higher than hybrid composite but statistically has not been proven. The result of the nanofilled composite is 279.02 $\mathrm{MPa}$ and the Hybrid composite is 243.45 $\mathrm{MPa}$. Post curing using dry heating is often used in the manufacture of composite indirect because high levels of polymerization or degree of conversion can be achieved. Degree of conversion is a measure of the percentage of carbon-carbon double bonds that have been converted to single bonds to form polymer resins. Increased monomer conversion will improve the physical properties and composite resistance. The conversion of monomers to polymers depends on a number of factors: the composition of the resin, filler and light transmission to the material.

Testing of compressive strength with cylindrical specimen size is a test method that many use as hardness test of composite. Making too small specimens can cause failure due to internal defects. With the size of the specimen with twice the height and diameter, the stress distribution on the composite surface will be more evenly distributed and the results can be better. ${ }^{5.8 .2}$

\section{CONCLUSION}

Compressive strength of hybrid composite after post curing with light box is greater than the nanofilled composite.

\section{REFERENCES}

1. Anusavice, K. J. 2003 Philip's Science of dental Material. Philadelpia: W.B Saunders Company. 351-376 pp.

2. Jain, V.V 2008 Evaluation of second generation indirect composite resins Departemen of dental material Indiana university.

3. Didier,D, 1997 Adhesive Metal-free restorations Current concept for the esthetic treatment of posterior teeth.p.125-13

4. Powers J.M and Sakaguchi R.L.2006, Craigh's Restorative Dental Material. News Delhi: Elsevier Inc. 78-85, 191-207pp.

5. Taminaldu. T. 2005 wear resistance four different posterior resin composite an invitro study:Departement of conservative dentistry $\&$ endodontic.

6. Dhuru.V.B., 2004. Contemporary Dental Material Oxford University press.

7. Riberio R.N., et al 2005 Microleakage evaluation of inlay fabricated with different materials Grad 12(2) 159-66pp. 